\title{
Fabrication and characterization of nano structured honeycomb absorbers and thermal analyses on solar air heating collector
}

\author{
S.Selvakumar ${ }^{1}$, T.R.Rajasekaran ${ }^{2 *}$, V.Sabarinathan ${ }^{3}$, T.Jeyakumaran ${ }^{4}$, R.V. Jeba \\ Rajasekhar $^{5}$
}

\author{
${ }^{1}$ Research Scholar (Reg. No: 12581), Department of Renewable Energy Science, Manonmaniam Sundaranar \\ University, Abishekapatti, Tirunelveli, Tamilnadu 627 012, India \\ ${ }^{2}$ Department of Renewable Energy Science, Manonmaniam Sundaranar University, Abishekapatti, Tirunelveli, \\ Tamilnadu 627 012, India \\ ${ }^{3}$ Department of Physics, Manonmaniam Sundaranar University, Abishekapatti, Tirunelveli,Tamilnadu 627012 , \\ India \\ ${ }^{4}$ PG \& Research Department of Physics, N.M.S.S.V.N. College, Nagamalai, Madurai,Tamilnadu 625 019, India \\ ${ }^{5}$ PG \& Research Department of Physics, Government Arts College, Melur, Madurai, Tamilnadu625 106, India \\ (Affiliated to Manonamniam Sundaranar University, Tirunelvel, Tamilnadu, India)
}

Article History:Received:11 november 2020; Accepted: 27 December 2020; Published online: 05 April 2021

\begin{abstract}
Fabrication of nano structured absorber is mandatory for reaping the enhanced thermal performance of solar collectors. In this connection, the nano carbon and aluminium composite was coated on aluminium substrate, which was similar to the hexagon shaped honey comb, and the solar absorber was developed. It was characterized through X-ray Diffractometer (XRD), Fourier Transform Infrared (FTIR) spectrometer and UV-Visible spectrophotometer (UV). It was also thermally analyzed not only in outdoor conditions but also in stagnant conditions in solar air heating collector. The research results pertaining to characterization of solar absorber showed that the crystallite size was in nano ranges and the nano particles had face-centre cubic structure. The research results pertaining to characterization of solar absorber also showed that the nano composite had excellent absorption in UV and visible region. The research result related to thermal analysis in outdoor environment revealed that the enhancements of temperature on solar absorbers coated with carbon and aluminium nano composite in the mass ratio of $60: 40,70: 30$ and 80:20 were $23.5^{\circ} \mathrm{C}, 25.1^{\circ} \mathrm{C}$ and $24.4^{\circ} \mathrm{C}$ respectively. The research result related to thermal analysis in stagnation environment also revealed that the enhancements of temperature on glass cover, carbon and aluminium nano composite coated absorber and working fluid were $69.4^{\circ} \mathrm{C}, 110.6^{\circ} \mathrm{C}$ and $99.0^{\circ} \mathrm{C}$ respectively. On the basis of research outcomes, it could be concluded that nano carbon and aluminium composite coated solar absorber would be used for photo thermal applications due to their desirable optical and thermal properties. It could also be concluded that nano carbon and aluminium composite coated solar absorbers would be used in photo thermal appliances due to their positive impact on thermal performances.
\end{abstract}

Keywords: Nano structured honey comb absorber, Fabrication, Characterization, Integration with solar air heating collector, Thermal characteristics

DOI:10.16949/turkbilmat.702540

\section{Introduction}

Solar absorber is a central component of any photo thermal collector. It influences significantly the thermal performance of photo thermal collector and related gadgets [1]. It is desirable to prepare energy efficient, environmental friendly and economically feasible solar absorbers. It is also desirable to characterize the prepared absorbers and evaluate the thermal efficacy of these absorbers in field conditions. It is worth mentioning here that many researchers have studied the properties of solar absorbers and their influences on thermal characteristics of solar collectors. Katumba et al. (2008) carried out research on the optical characteristics of solar absorptive coatings with the chemical composition of nano carbon and metal oxides. The research result revealed that the solar absorptance of nano carbon and nickel oxide coating deposited on metal substrate was $84 \%$. The research result also revealed that the same solar absorptance of nano carbon and zinc oxide coating deposited on the same metal substrate was 71\% [2]. Sudharlin Paul et al. (2017) carried out research on the thermal characteristics of solar collector integrated with absorber that had nano carbon mixed absorptive coating on copper substrate. The research result revealed that the sizes of carbon crystallites in absorptive coating were in nano ranges that were confirmed through SEM analysis. The research result also revealed that the maximum temperature elevation of working fluid was $43.5^{\circ} \mathrm{C}$ in solar collector integrated with the similar brand of absorber that had the same nano carbon mixed absorptive coating on copper substrate [3]. Vasantha Malliga et al. (2017) carried out research on nanographite and $\mathrm{CuO}$ coated absorber and evaluated the

*Corresponding author: S.Selvakumar

Research Scholar (Reg. No: 12581), Department of Renewable Energy Science, Manonmaniam Sundaranar University, Abishekapatti, Tirunelveli, Tamilnadu 627 012, India 
thermal performance of solar air heating collector integrated with the same nanographite and $\mathrm{CuO}$ coated absorber. The research outcome revealed that the sizes of graphite and $\mathrm{CuO}$ crystallites in absorptive coating were in nano ranges that were confirmed through XRD analysis. The research outcome also revealed that the maximum temperature of working fluid was $59.4^{\circ} \mathrm{C}$ and the maximum thermal performance of solar collector integrated with absorber that had nano graphite and $\mathrm{CuO}$ mixed absorptive coating on aluminium substrate was $68.0 \%$ [4]. Jeyasankar et al. (2018) carried out research on nano structured solar absorbers and their utilisation in applied solar devices. The research outcome revealed that nano carbon and $\mathrm{MnO}_{2}$ coated absorbers could be developed by spray coating method. The research outcome also revealed that the crystallite sizes in the coatings of carbon and $\mathrm{MnO}_{2}$ based absorbers were in nano ranges. The observation on research outcomes revealed that the thermal durability and thermal efficacy of the nano carbon and $\mathrm{MnO}_{2}$ (in mass concentration of 70:30 ratio) coated absorbers were acceptable in connection with their utilization in the solar collectors [5]. Saravanan et al. (2019) carried out research on nano composite coated solar absorbers and their utilisation in application sectors. The research result revealed that the crystallite sizes in the coatings of graphite and $\mathrm{TiO}_{2}$ coated absorbers were in nano ranges. The research result also revealed that the operative temperature of nano graphite and nano $\mathrm{TiO}_{2}$ coated absorber varied from $28.4^{\circ} \mathrm{C}$ to $39.2^{\circ} \mathrm{C}$. The observation on research result also revealed that the stagnation temperature of the solar collector integrated with absorber that had nano graphite and $\mathrm{TiO}_{2}$ mixed absorptive coating on metal substrate was $87.3^{\circ} \mathrm{C}$ and the range of increase of temperature of fluid was from 6.4 to $7.1^{\circ} \mathrm{C}$ [6]. Selvakumar et al. (2019) carried out research on supplementary heating of fluid with solar collector integrated with absorber that had nano carbon and $\mathrm{Cr}_{2} \mathrm{O}_{3}$ mixed absorptive coating on metal substrate. The research result revealed that the crystallite size in absorptive coating effected on solar absorber was $36 \mathrm{~nm}$. The research result also revealed that the stagnation temperature of solar collector with the prepared nano structured absorber was $85.0^{\circ} \mathrm{C}$. The observation on research result revealed not only the temperature enhancement of fluid that varied from 5.3 to $5.7^{\circ} \mathrm{C}$ but also the instantaneous performance of collector that ranged between 53 to 54 $\%$ [7]. As there were limited studies not only on solar absorber that had nano carbon and metal coatings but also on solar air heating collector integrated with absorber that had the same nano carbon and metal coatings on aluminium substrate, the present research work has been carried out with the objectives such as (i) preparation of nano carbon and aluminium coated solar absorber (ii) characterization of coating effected on solar absorber and (iii) thermal analysis on small scale $(400 \mathrm{~mm} \times 200 \mathrm{~mm}$ ) solar absorber, (iv) thermal analysis on large scale $(2000 \mathrm{~mm} \times 1000 \mathrm{~mm})$ solar absorber, (v) thermal analysis on solar air heating collector integrated with solar absorber that had nano carbon and metal coating on aluminium substrate. The preparation, characterization and thermal analyses have been presented and the research outcomes have been elaborately discussed in this research paper.

\section{Materials and methods}

In the present research, the bituminous coal blocks were collected. They were powdered in nano sizes by using high energy vertical planetary ball mill. There were four stainless steel mill jars in ball mill and $10 \mathrm{~g}$ of bituminous coal was loaded in each of these jars. The demineralised water of $10 \mathrm{ml}$ was added in mill jars. There were 56 agitate balls and each ball size was $10 \mathrm{~mm}$. The angular velocity of mill jar was fixed to be 150 $\mathrm{rpm}$. The milling was carried out for two hours with suitable period of breaks. The powdered samples were collected and they were dried at $400^{\circ} \mathrm{C}$ for two hours. The dried samples were stored and the stored samples were used for further studies in this research [8].

The prepared carbon powder was mixed with nano sized aluminium in different proportions. The mixed carbon and nano sized aluminium powder was stirred by using mechanical stirrer in solar emulsion used in solar industries [9]. The prepared solar absorptive solution was used for coating on solar absorbers.

The metal sheets were commercially procured. They were properly cleaned and pre-treated by adhering standard procedures. The prepared absorptive solution was sprayed on these cleaned and pre-treated metal plates. While the spray rate was $10 \mathrm{ml} \mathrm{min}^{-1}$ with compressed air as carrier gas, the distance between spray head and metal plate was kept to be $15 \mathrm{~cm}$ [4]. The coated metal sheets were cured and they could serve as solar absorbers.

The prepared solar absorbers were thermally analysed so as to know their thermal durability in photo thermal collectors. In this connection, they were kept in hot air oven. After the test tenure of four hours in hot conditions in hot air oven, the heated solar absorbers were taken out. They were cooled in outdoor conditions as per Bureau of Indian Standards (BIS) specifications [10]. The peeling of coating, if any, was manually checked. In addition, the fading of coating, if any, was visually inspected.

The coatings on solar absorbers were characterised through XRD, FTIR and UV analyses and the structural, functional group and reflectance spectra outcomes were obtained. It is to be noted that all the characterization techniques were carried out at room temperature [11]. The crystalline nature of the carbon or bituminous coal (BC) powder, aluminium nano particles (Al-NPs) and various ratio composites of BC:Al-NPs (80:20, 70:30 and 60:40) was explored by powder X-Ray diffraction patterns recorded in the $2 \theta$ range from $10^{\circ}$ 
to $80^{\circ}$ using the XPERT-PRO diffractometer with the wave length of $1.5406 \AA$ [12]. The FTIR spectra of the bituminous coal powder, Al-NPs and various ratio composites of BC:Al-NPs (80:20, 70:30 and 60:40) was recorded in the range of 4000 to $400 \mathrm{~cm}^{-1}$ using the PERKIN ELMER (Spectrum Two, model-C9217) spectrophotometer with the $\mathrm{KBr}$ pellet technique [13]. The diffuse reflectance spectra of the bituminous coal powder, Al-NPs and various ratio composites of BC:Al-NPs (80:20, 70:30 and 60:40) was recorded in the range of 200 and $800 \mathrm{~nm}$ using UV-Vis (SHIMADZU-2400) spectrophotometer with $\mathrm{BaSO}_{4}$ as a non-absorbing standard reference [14].

In the present research, the cleaned and pre treated metal sheets were cut into small scale (400 $\mathrm{mm} \mathrm{x}$ $200 \mathrm{~mm})$ and large scale $(2000 \mathrm{~mm}$ and $1000 \mathrm{~mm}$ ) metal substrates. The metal substrates were coated with the prepared absorptive solution by spray coating method and they were cured before utilising them as solar absorbers. It is to be noted that the length of the large scale absorber, breadth of the large scale absorber and thickness of the absorber were fixed as per BIS specifications [10]. It is also to be noted that variations in the sizes of the sides of hexagon structured absorber were purposely fixed so as to have relatively higher inlet energy to the solar collector.

The prepared small scale solar absorbers were thermally analysed in outdoor environment so as to know thermal enhancements on them with varied meteorological conditions. In this connection, the solar absorbers were fixed on the specially fabricated test stands so as to be free from dusts, shadows and other influencing materials during the experimental tenure [10]. As these solar absorbers were kept in suitable test stands in outdoor conditions, there was a significant increase in temperature on these black coated solar absorbers. The increase in temperature on these solar absorbers was periodically measured. In addition, the levels of influencing parameters such as solar radiation, ambient temperature and wind speed were systematically measured during experimental tenure [15].

In the present research work, a zinc plate of size $3 \mathrm{~m}^{2}$ was commercially procured. It was observed that the procured plate had homogeneity with same thickness and suitable roughness throughout the plate. The hexagon structured honeycomb carrier with a length of $2000 \mathrm{~mm}$ breadth of $35 \mathrm{~mm}$ and thickness of $0.51 \mathrm{~mm}$ were prepared separately from the procured zinc plate. Similarly, eight numbers of carriers were developed and they were integrated together. While the cross sectional view and design of single honeycomb carrier have been presented in Figure 1 and 2 respectively, the design of multiple honeycomb carriers have been presented in Figure 3. The developed carrier system was coated with bituminous coal and aluminium mixed solution by spray coating method. This absorber system was subsequent integrated in solar air heating collector. It is to be noted here that the solar air heating collector had other integral components such as toughened glass cover, rock wool insulation and aluminium channel sections in opt dimensions. The developed solar collector, whose photograph has been presented in Figure 4, was thermally analysed in field conditions so as to know the stagnation temperature of solar air heating collector. In this connection, the solar air heating collector was fixed on the specially fabricated test stands so as to be free from dusts, shadows and other influencing materials during the experimental tenure [10]. As the solar collector was kept in suitable test stand in field conditions, there was a significant increase in temperature in air heating collector. The stagnation temperature of the solar collector was found along with the levels of influencing parameters such as solar radiation, ambient temperature and wind speed [15].

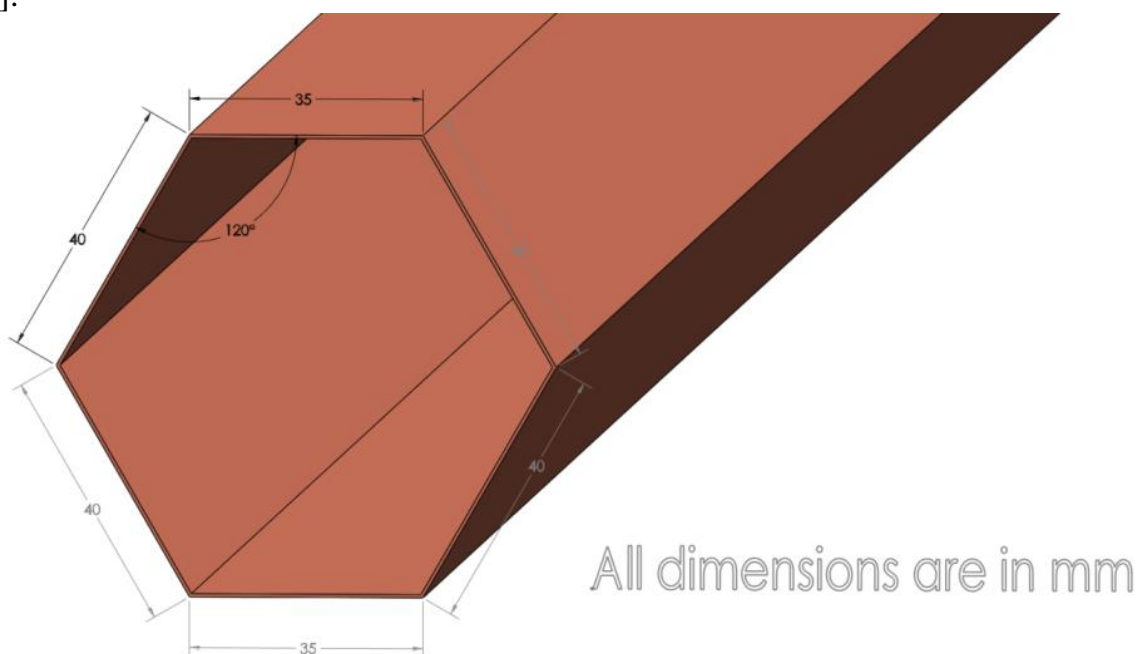

Fig. 1 Cross sectional view of honeycomb carrier 


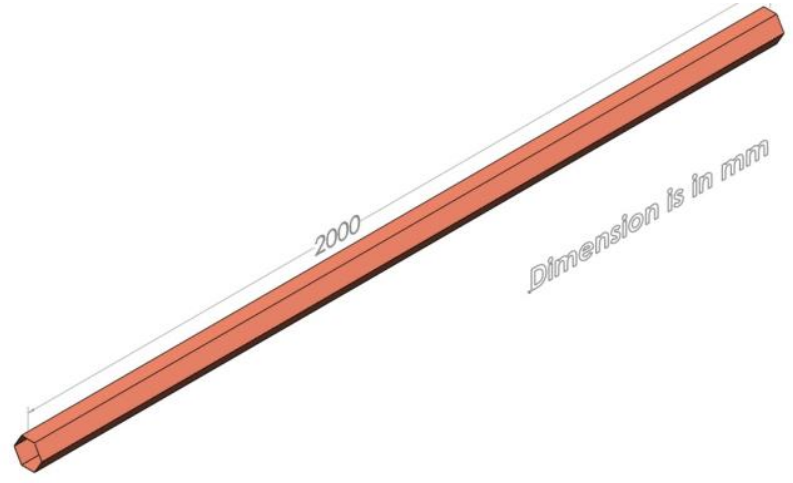

Fig. 2 Design of single honeycomb carrier

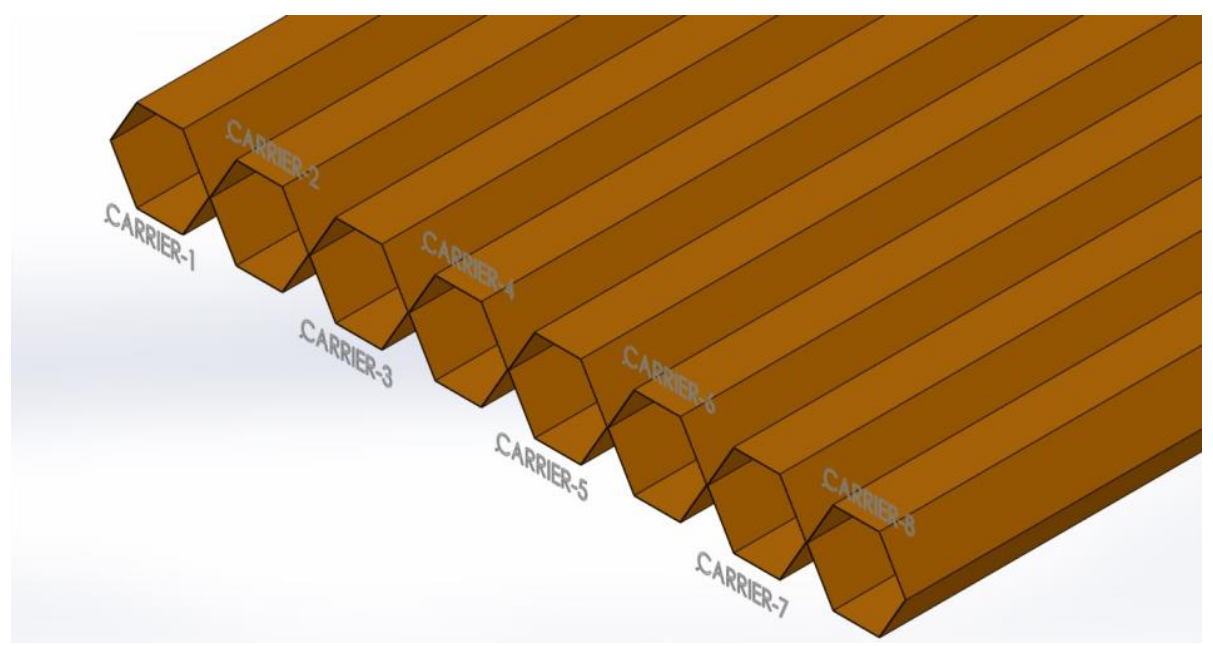

Fig. 3 Design of multiple honeycomb carriers

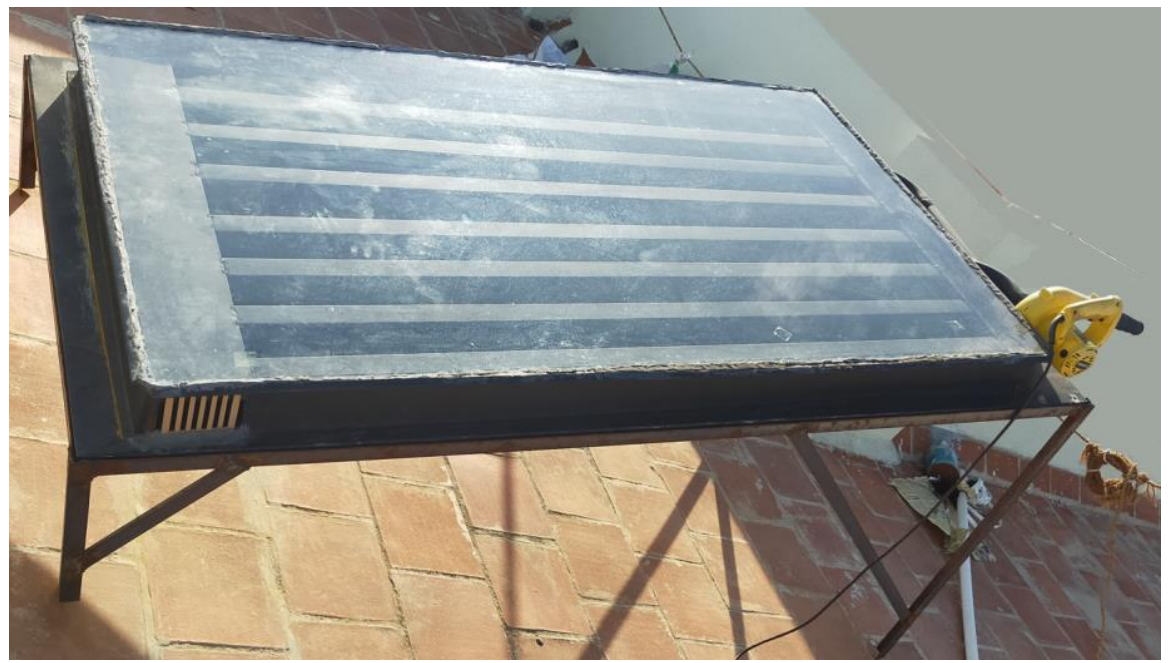

Fig. 4 Developed honeycomb solar air heating collector setup

\section{Results and discussion}

As the objectives of the present research included preparation of solar absorber, characterisation of coating on solar absorber and thermal analyses on solar absorbers and solar air heating collector, they were separately materialised by adopting standard methodology and the experimental outcomes of the present research have been individually documented. While the specifications of the solar absorber have been recorded in Table 1, the level of thermal enhancements on solar absorbers with variations in different levels of incident solar radiation have been recorded in Table 2. In addition, the recorded maximum temperature of components of solar air heating collector in stagnant conditions has been recorded in Table 3. At the same time, the 
characterisation outcomes with reference to XRD, FTIR and UV analyses have been recorded from figure 5 to figure 6 .

In the present research, the material aluminium was used as substrates of solar absorbers. The nano carbon and aluminium mixed absorptive coating was deposited on aluminium substrates and solar absorbers were prepared. The thermal durability test on solar absorbers showed that the outside layer could endure neither fading of coating nor peeling of coating in stagnant and operative conditions. It also showed that the coating on solar absorbers could withstand the degree of temperature in stagnant and operative conditions of solar air heating collectors [10].

Fig. 5. depicts the powder XRD patterns of the bituminous coal, Al-NPs and different ratio (80:20, 70:30 and 60:40) composites of BC:Al-NPs.

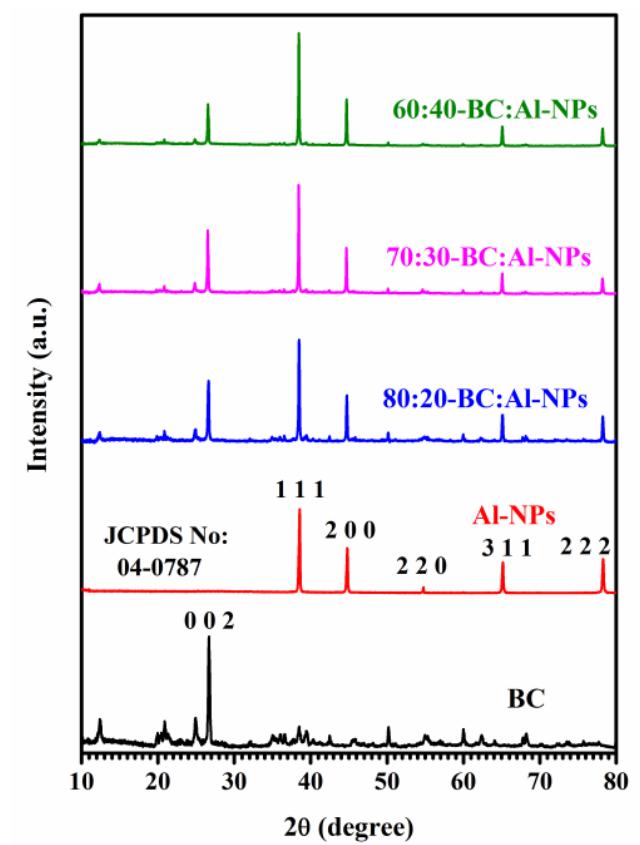

Fig. 5 XRD pattern of the BC, Al-NPs and composite of

BC:Al-NPs (with the ratio of 80:20, 70:30 and 60:40)

In the diffractogram, the bituminous coal (BC) exhibited an intense XRD peak at $26.68^{\circ}\left(\begin{array}{lll}0 & 0 & 2\end{array}\right)$ that would correspond to the graphitic carbon structure. The other peaks in XRD pattern of BC indicated the crystalline form of crystals and also unidentified metal oxide. The peaks of pure aluminium nanoparticles (AlNPs) appeared at $38.56^{\circ}, 44.78^{\circ}, 54.76^{\circ}, 65.15^{\circ}$ and $78.27^{\circ}$ would correspond to (1 111$)$, (2 000$),\left(\begin{array}{llll}2 & 2 & 0\end{array}\right),\left(\begin{array}{lll}3 & 1 & 1\end{array}\right)$ and ( $\left.\begin{array}{lll}2 & 2 & 2\end{array}\right)$ plane respectively. The analytical results showed that the Al-NPs had face-centre cubic structure (JCPDS No-04-0787) [16]. The Debye-Scherrer formula has been used to find the crystallite size and it was found that the crystallite size was 70nm. The XRD pattern could exhibit the peaks of all BC:Al-NPs composites and so it was confirmed that the BC:Al-NPs composites have been formed.

Fig. 6. represents the FTIR spectrum of the bituminous coal, Al-NPs and different ratio (80:20, 70:30 and 60:40) composites of BC:Al-NPs. The FTIR spectrum was utilised to predict the functional group of BC and influence of Al-NPs mixing with BC. It is to be noted here that the BC comprised carbon with different bonding structure in general. The peak observed around $1087 \mathrm{~cm}^{-1}$ of all composites in FTIR spectra was assigned to stretching vibration of the aliphatic ether oxygen bond [17]. The doublet peak appeared around 1032 and $1008 \mathrm{~cm}^{-1}$ were assigned to stretching vibration of the $\mathrm{Si}-\mathrm{O}-\mathrm{Si}$ or $\mathrm{Si}-\mathrm{O}-\mathrm{C}$ respectively. Therefore, it was confirmed that silicate-based minerals were present in BC. 


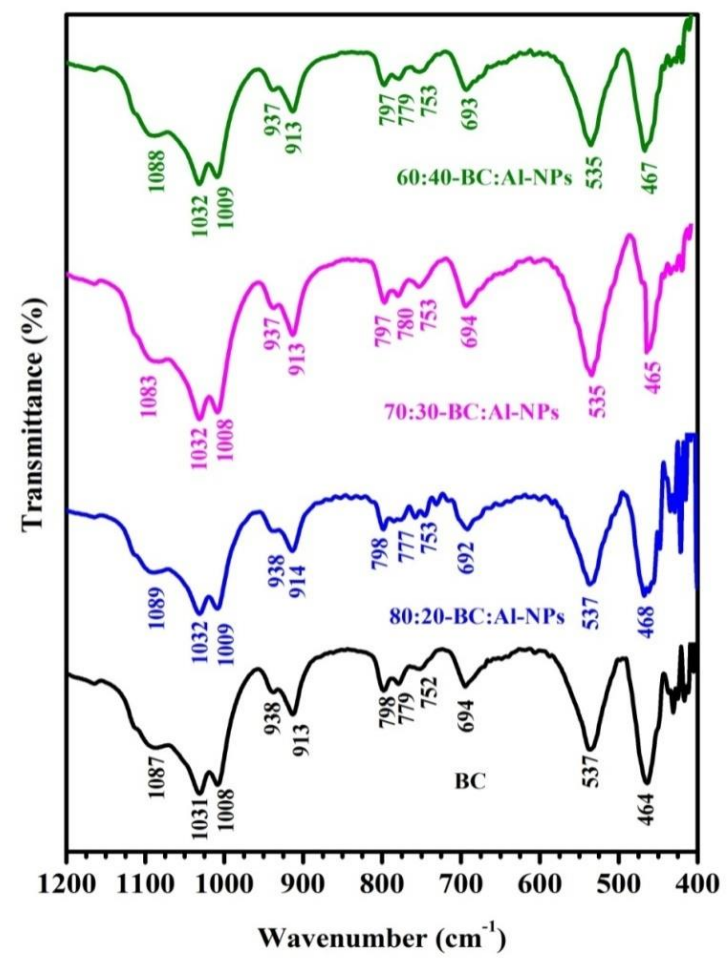

Fig. 6 FTIR spectra of the BC and BC:Al-NPs

(in the ratios of 80:20, 70:30, and 60:40)

The peaks appeared around 940 and $913 \mathrm{~cm}^{-1}$ were assigned to hydroxyl in carboxylic acid structure. The week peaks located around 800, 779, 753, and $694 \mathrm{~cm}^{-1}$ would correspond to the out-of-plane of C-H vibration of the aromatic ring bonding with three aromatic hydrogens, four adjacent aromatic hydrogens and five adjacent hydrogens respectively [18]. Also, the strong peaks located around 535 and $465 \mathrm{~cm}^{-1}$ would correspond to the $\mathrm{Fe}-\mathrm{O}$ and $\mathrm{Zn}-\mathrm{O}$ bond respectively [19]. It was found that the peak arrangements were in good agreement with earlier review reports.

Fig. 7. shows the diffuse reflectance spectra of the bituminous coal, Al-NPs, and different ratios (80:20, 70:30, 60:40) composites of the BC:Al-NPs.

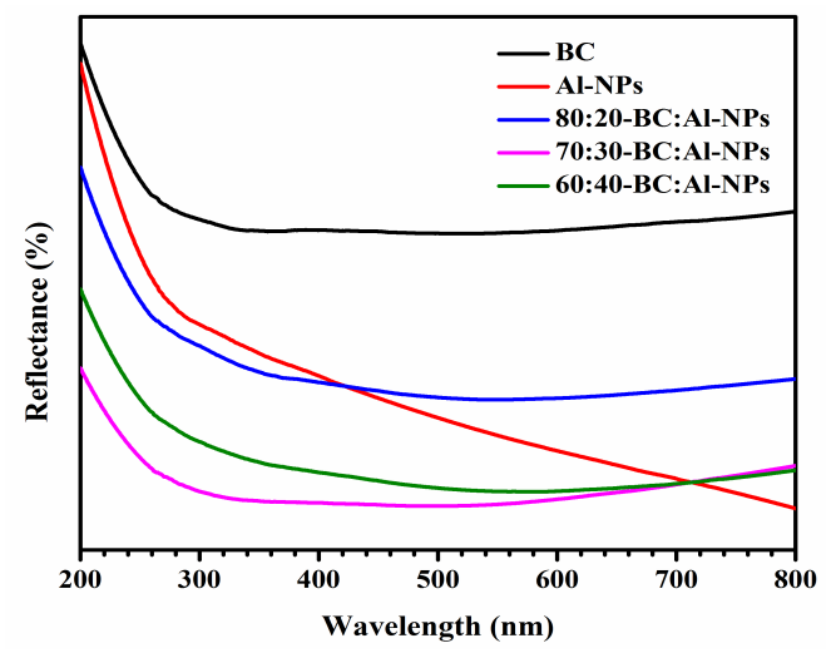

Fig. 7 Reflectance spectra of BC, Al-NPs and composite of BC:Al-NPs (with the ratio of 80:20, 70:30, and 60:40)

The reflectance spectra showed that there was an excellent absorption in the entire UV and also visible region. Hence, the UV outcomes showed that the BC: Al-NPs composite might be acting as good absorber material for the solar spectrum [20].

Table 1 Specifications of solar absorber

\section{Description of solar absorber}

Materials and dimensions of solar absorber 
Fabrication and characterization of nano structured honeycomb absorbers and thermal analyses on solar air heating collector

\begin{tabular}{|l|c|}
\hline Material & Aluminium \\
\hline Thickness of material & $0.20 \mathrm{~mm}$ \\
\hline $\begin{array}{l}\text { Breadth of material } \\
\text { (Small scale solar absorber) }\end{array}$ & $20 \mathrm{~mm}$ \\
\hline $\begin{array}{l}\text { Length of material } \\
\text { (Small scale solar absorber) }\end{array}$ & $40 \mathrm{~mm}$ \\
\hline $\begin{array}{l}\text { Breadth of material } \\
\text { (Large scale solar absorber) }\end{array}$ & $1000 \mathrm{~mm}$ \\
\hline $\begin{array}{l}\text { Length of material } \\
\text { Large scale solar absorber) }\end{array}$ & $2000 \mathrm{~mm}$ \\
\hline Coating on solar absorber & Nano carbon and aluminium coating \\
\hline
\end{tabular}

In the present research, a total of three number of small scale solar absorbers (400 $\mathrm{mm} \times 200 \mathrm{~mm})$ were prepared. While the first absorber had absorptive coating with BC:Al-NPs in the mass ratio of 60:40, the second and third absorbers had absorptive coating with BC:Al-NPs in the mass ratio of 70:30 and 80:20 respectively. They were thermally analysed in outdoor environment and the thermal enhancements on these solar absorbers with variations in meteorological conditions have been recorded. It was noted that the level of solar radiation varied from 398.6 to $850.7 \mathrm{~W} / \mathrm{m}^{2}$. It was also noted that the ambient temperature varied from 29.6 to $33^{\circ} \mathrm{C}$ and wind speed ranged between 0.2 to $0.9 \mathrm{~m} / \mathrm{s}$ during experimentation on solar absorbers in outdoor environment.

The stagnation temperature is the temperature of a solar device under no flow and outdoor conditions with respect to time during sunshine hours. It is therefore the fluid temperature in a solar collector with respect to time during sunshine hours where no useful energy is taken from solar collector. It is also therefore the fluid temperature in a solar collector as a result of mainly the levels of incident solar radiation and also ambient temperature [21]. In the present research, one large scale solar absorber $(2000 \mathrm{~mm} \times 1000 \mathrm{~mm})$ that had the absorptive coating with BC:Al-NPs in the mass ratio of 70:30 was prepared. This solar absorber was integrated along with toughened glass cover, rock wool insulation, aluminium channel section, aluminium angle section and aluminium bottom sheet in a conventional photo thermal collector [10]. The solar collector was kept in stagnant conditions in outdoor environment and it was tested. It was noted that the level of solar radiation varied from 402.4 to $827.5 \mathrm{~W} / \mathrm{m}^{2}$. It was also noted that the ambient temperature varied from 29.8 to $32.7{ }^{\circ} \mathrm{C}$ and wind speed ranged between 0.1 to $0.5 \mathrm{~m} / \mathrm{s}$ during experimentation on solar air heating collector in outdoor environment.

Table 2 Temperature enhancements on BC: Al-NPs composite coated solar absorber in outdoor conditions

\begin{tabular}{|c|c|c|c|}
\hline \multirow{2}{*}{$\begin{array}{c}\text { Solar radiation } \\
\left(\mathrm{W} / \mathrm{m}^{2}\right)\end{array}$} & \multicolumn{4}{|c|}{ Temperature enhancement $\left({ }^{\circ} \mathrm{C}\right)$} \\
\cline { 2 - 5 } & $\begin{array}{l}\text { On solar absorber with } \\
\text { BC:Al-NPs in the mass } \\
\text { ratio of 60:40 }\end{array}$ & $\begin{array}{l}\text { On solar absorber with } \\
\text { BC:Al-NPs in the mass } \\
\text { ratio of 70:30 }\end{array}$ & $\begin{array}{l}\text { On solar absorber with } \\
\text { BC:Al-NPs in the mass } \\
\text { ratio of 80:20 }\end{array}$ \\
\hline 398.6 to 550.2 & 5.9 & 6.2 & 6.1 \\
\hline 550.2 to 702.8 & 8.0 & 8.6 & 8.3 \\
\hline 702.8 to 850.7 & 9.6 & 10.3 & 10.0 \\
\hline
\end{tabular}

Table 3 Temperature of components of solar air heating collector in stagnant conditions

\begin{tabular}{|l|c|}
\hline Components and working fluid & Maximum temperature $\left({ }^{\circ} \mathrm{C}\right)$ \\
\hline Glass cover & 69.4 \\
\hline BC: Al-NPs (70:30) composite coated solar absorber & 110.6 \\
\hline Working fluid & 99.0 \\
\hline
\end{tabular}

The research result related to thermal analysis in outdoor environment revealed that the enhancements of temperature on solar absorbers coated with carbon and aluminium nano composite in the mass ratio of 60:40, $70: 30$ and $80: 20$ were $23.5^{\circ} \mathrm{C}, 25.1^{\circ} \mathrm{C}$ and $24.4^{\circ} \mathrm{C}$ respectively. The research result related to thermal analysis in stagnation environment also revealed that the enhancements of temperature on glass cover, carbon and aluminium nano composite coated absorber and working fluid were $69.4{ }^{\circ} \mathrm{C}, 110.6{ }^{\circ} \mathrm{C}$ and $99.0{ }^{\circ} \mathrm{C}$ respectively. It is worth mentioning here that the present solar air heating collector had three special features and the obtained research results on solar absorber and air heating collector could be correlated to these three special features. The first feature was the presence of optimized BC: Al-NPs (70:30) composite coated solar absorber for having increased absorption of incident radiation [22]. The second feature was the presence of honey comb structure on solar absorber for having more heating effect and heat transfer to working fluid [23]. The third feature was the fabrication of solar air heating collector with selected materials in specified dimensions [24]. By consolidating 
these three features, the obtained research results on solar absorber and air heating collector could be mainly attributed with optical characteristics of nano coating on solar absorber, thermal characteristics of the material, size and structure of the honey comb based absorber, usage of selected materials as primary components, usage of selected materials as secondary components and utilization of materials in specified dimensions [25, 26]. The obtained research results on solar absorber and air heating collector could also be mainly attributed with the intensities of incident solar radiation, levels of influencing meteorological parameters and subsistence of stagnation conditions in solar air heating collector [27].

\section{Conclusion}

On the basis of research outcomes, it could be concluded that nano carbon and aluminium coated solar absorbers would be used for photo thermal applications due to their desirable optical and thermal properties. It could also be concluded that nano carbon and aluminium coated solar absorbers would be used in photo thermal appliances due to their positive impact on thermal performances.

\section{Acknowledgement}

The authors are grateful to RUSA for providing the characterization facilities at Manonmaniam

Sundaranar University, Tirunelveli, Tamilnadu, India

\section{References}

John A.Duffe, William A.Beckman, Solar engineering of thermal processes, A Wiley Inter science Publications, New York, U.S.A. (1980)

G. Katumba, L. Olumekor, A. Forbes, et al., Optical, thermal and structural characteristics of carbon nanoparticles embedded in $\mathrm{ZnO}$ and $\mathrm{NiO}$ as selective solar absorbers, Solar Energy Materials and Solar Cells, 92(10), 1285-1292 (2008)

P.H. Sudharlin Paul, R.V. Jeba Rajasekhar, Thermal analyses on solar collectors with nano carbon coated absorbers, International Journal of Innovative Science, Engineering \& Technology, 4(5), 181-185 (2017)

T. Vasantha Malliga, R.V. Jeba Rajasekhar, Preparation and characterization of nanographite-CuO based absorber and performance evaluation of solar air heating collector. Journal of Thermal analysis and Calorimetry, Springer Publications, 129(1), 233-240 (2017)

P. Jeyasankar, R.V. Jeba Rajasekhar, Preparation, Characterization and Evaluation of Thermal Efficacy of Nano carbon- $\mathrm{MnO}_{2}$ Coated Solar Absorber, International Journal of Scientific Research in Physics and Applied Sciences, 6(2), 52-54 (2018)

N.S. Saravanan, R.V. Jeba Rajasekhar, Impact of operative temperature of nano composite coated absorber on thermal performance of solar collector, International Journal of Research and Analytical Reviews, 5(4), 612-615 (2019)

S. Selvakumar, T.R. Rajasekaran, V. Sabarinathan et al., Thermal analysis on solar collector for supplementary heating of hot fluid, International Journal of Research in Advent Technology, 7(4), $56-57$ (2019)

K.K. Chattopadhyay, A.N. Banerjee, Introduction to Nanoscience and Technology. PHI Learning Private Limited, New Delhi, India (2012)

R.V. Jeba Rajasekhar, Experimental investigations on components, heating systems and test set-ups in photothermal applications, Ph.D. thesis., Madurai Kamaraj University, Madurai, India (2018)

10. BIS Specifications, IS 12933, Indian standard solar flat plate collector specifications. New Delhi, India (2003)

Anthony R. West, Solid state chemistry and its applications, John Wiley \& Sons Publications, West Sussex, U.K. (2014)

B.D. Cullity, Elements of X Ray diffraction, Addison Wesley Publishing Company, Boston MA, U.S.A. (2018)

John R.Ferraro, K.Krishnan, Practical Fourier Transform Infrared Spectroscopy: Industrial and Laboratory chemical analysis, Academic Press, California, U.S.A. (1990)

B.J. Clark, T. Frost, M.A. Russell, UV Spectroscopy Techniques, Instrumentation and Data handling, Chapman \& Hall, London, U.K. (1993)

Bennett Widyolar, Lun Jiang, Jonathan Ferry et al., Non tracking East-West XCPC Solar thermal collector for 200 celsius applications, Applied energy, 216, 521-533 (2018)

P. Giridhar, B. Weidenfeller, S. Zein El Abedin et al., Electrodeposition of iron and iron-aluminium alloys in an ionic liquid and their magnetic properties, Physics Chemistry Chemical Physics, 16, 9317-9326 (2014)

Weiquing Zhang, Shuguang Jiang, Kai Wang et al., Thermogravimetric Dynamics and FTIR Analysis on Oxidation Properties of the Low-RanK Coal at Low and Moderate Temperature, Int. J. of Coal Preparation and Utilization, 35(1), 39-50 (2014) 
Shuxing Qiu, Shengfu Zhang, Xiaohu Zhou et al., Structural Characterization of Four Chinese Bituminous Coals by X-Ray Diffraction, Fourier-Transform Infrared Spectroscopy and X-Ray Photoelectron Spectroscopy, Characterization of Minerals and Materials, 11-22 (2019)

Fredy Colpas-Castillo, Arnulfo Taron-Dunoyer, Jairo Mercado-Camargo, Physicochemical characterization of bituminous carbons from the Colombian Caribbean region, Contemporary Engineering Sciences, 11(64), 3187-3195 (2018)

Nafisa Begum, Debashish Chakravarty, Bhabani Sankar Das, Estimation of Gross Calorific Value of Bituminous Coal using various Coal Properties and Reflectance Spectra, Int. J. of Coal Preparation and Utilization, 1-7 (2019)

Elimar Frank, Franz Mauthner, Stephan Fischer, Overheating prevention and stagnation handling in solar process heat applications, Technical Report, International Energy Agency IEA SHC Task 49 SolarPACES, U.S.A. (2015)

K. Uma Maheswari, R.V. Jeba Rajasekhar, Absorptive coating with nano sized carbon and aluminium oxide: Preparation, characterization and estimation of thermal enhancement in solar absorber, Int. J. of Recent Scientific Research, 6(3), 3226-3228 (2015)

Mohammad Faisal Hasan, Kyaw Thu, Takahiko Miyazaki et al., Study of honeycomb solar air heater: Optimisation of honeycomb dimensions for maximum solar heat gain, The Proceedings of the Symposium on Environmental Engineering, Japan Society of Mechanical Engineers, Japan (2017)

R.V. Jeba Rajasekhar, Comparison of thermal performance of two types of solar air heaters in a fruit dehydration unit, M.Phil., dissertation, Madurai Kamaraj University, Madurai, India (1996)

H.P. Garg, J. Prakash, Solar Energy Fundamentals and Applications, McGraw Hill Publications, New Delhi, India (2000)

Soteris A.Kalogirou, Solar Energy Engineering Processes and Systems, Academic Press, Cambridge, U.S.A. (2013)

Soteris A.Kalogirou, Solar thermal collectors and applications, Progress in Energy and Combustion Science, 30(3), 231-295 (2004) 